waste money and perhaps do more harm than good when we invest only in pet projects. That approach leads to waste, not real, sustainable change. We need a new approach, one of systemic change. When we make investments and champion policies that support developing countries in building capacity, including the establishment of an effective public health infrastructure, then we will see long-term, sustainable improvements that lead to economic advancement, better health, and improved global living conditions.

In the short term, we can fulfill our immediate responsibilities to our own people by improving our ability to inspect imported goods and food and insist that imports meet our own public health standards. As we did when we boycotted grapes and bought only union lettuce, we can each choose to spend a few extra cents to buy goods made by union labor or from companies that respect worker health and safety standards. We can insist that our government make massive grants to and investments in the WHO. We can insist that our government pay off as soon as possible its UN dues, which are nearly $\$ 1$ billion in arrears, according to the US (the UN believes we owe billions more). We can work toward finding common ground between the North and South on environmental issues so that we don't see another breakdown in negotiations like that in November's summit on global warming at The Hague. And we can curb our own appetite for polluting vehicles, chemicals that destroy environments, and drugs like cocaine whose production distorts rural economies.
We have a tradition in this country of rebuilding without malice. Had President Lincoln lived to fulfill the promise of his second inaugural address, "to bind up the nation's wounds," we might have had a less punitive Reconstruction period and might have avoided the corruption that followed it. When General George Marshall announced the Marshall Plan under the Truman Administration in 1947, he said, "Any government that is willing to assist in the task of recovery will find full cooperation... on the part of the United States." The same Europe that 50 years ago was on the verge of starvation was soon the site of stable democracies and flourishing economies. Many trace the emergence of the European Union back to the Marshall Plan, which emphasized free trade across borders and international cooperation even with the vanquished.

As we so generously assisted those we defeated in war, so let us assist our trade partners. Let us help them set standards for democratization of decision-making, for fair wages and improved working conditions, for cleaner environmental practices, for cross-border cooperation. Let us support them in investing in public health, education, economic development, and other activities that will lead to sustainable change and humane living conditions. The earliest Americans understood the wholeness of the universe, the relationship between people and the earth, the connection of all things. Without the technology of space travel, they had a clear view of our globe. We would do well to see the world through their eyes.

- Judith Kurland

\title{
A Few Words of Thanks
}

A little more than two years ago Tony Robbins, the departing editor of Public Health Reports, and Art Lawrence, of the Surgeon General's office, asked me if I would step in for a little while and serve as editor of the journal while a permanent editor was sought. I happily agreed. After all, six months of working with and on issues that mattered to me, in a different forum, with people who creatively approached public health issues and could write about them, seemed more a gift to me than from me. The six months turned into almost two years, and I have enjoyed them. I have enjoyed them because of the wonderful work I see being done around the country, because of the passionate concern I see from practitioners, academics, policy makers, and students, because of the wonderful colleagues with whom I have worked.

Had I known it was going to be two years, I would have staffed up, and thereby relieved Judy Kaplan, Scientific Editor, of the enormous additional burden she has shouldered in producing the journal. Judy has done more than any editor should have to in getting each issue out. It is no understatement to say that every issue of the past two years is hers. In the absence of any other permanent staff, she and I were saved from failure and catastrophe by many colleagues who volunteered their time-including three volunteers who read manuscripts, brainstormed suggestions for articles, called friends and colleagues for contributions, suggested new ideas and approaches, and provided constant encouragement: Ken Brown of the Health Resources and Services Administration (HRSA), Mark Yessian of the DHHS Office of Inspector General, and Anne Fidler, academic liaison to the Boston University School of Public Health from the Centers for Disease Control and Prevention. They have been great support and great friends. Anne deserves special mention because week in and week out she was my partner in producing this journal, and deserved to be listed on the masthead as co-editor.

Janice Lesniak for the first year and Maureen Osolnik for the second provided essential administrative support and advice. This temporary federal employee is grateful for their knowledge, patience, and problem-solving skills. Mary Fisher has given us her time, good work, and unfail- 
ing kindness and calming presence. Tina DeLima time and time again bailed us out of those interminable work crunches, and seemed to do in hours what for others required days. Josh Trufant and Naomi Aluf, both of unfailing good humor, have been an integral part of our team and share in our success, as do Olivia Waishek, Polly Hoppin, Gary Kleinman, and Jeff Lazar. My personal thanks to Jeri Zeder for her invaluable assistance with everything that has my name on it.

Len Duhl, Peter Lee, and Julie Michaels made the special-focus double issue on the Healthy Communities movement possible. It is a meaningful contribution to the field.

HRSA's Boston office has provided incalculable dayto-day and moral support, including Peter Rubbo's computer expertise, and the Public Health Service and
National Library of Medicine staffs have been wonderfully patient and supportive. I know that Bob Rinsky, the long-awaited and much-welcomed permanent editor will receive from them the interest, kindness, and help I have counted on. I already enjoy his fresh view and gentle enthusiasm.

At every critical moment, Surgeon General David Satcher has consistently and clearly expressed and provided his support for the continued existence and independence of the journal.

All of these have made the journal strong, but you, our readers, reviewers, and authors, through your letters, comments, and contributions, have made PHR fresh, relevant, and responsive. As I said, I have enjoyed the experience and I am grateful for this opportunity.

- Judith Kurland

\section{A Message from the New Editor}

I am writing this message as the new editor of a grand, 122-year-old public health journal. I am struggling to find the words to introduce myself and express how fortunate I feel and how much I am looking forward to the challenges that lie ahead. After more than 25 years as a public health practitioner, I hadn't expected to be at a loss for words in trying to explain precisely where I plan to take this journal. I would like to tell you exactly what you can expect, but of course that would require a fixed knowledge of where public health stands and where it is going. At this writing, I do not even know who the president of the United States is going to be, let alone the status of public health as it will evolve in the new administration and beyond. The phases of this evolution are not preordained, and will be determined by all of us who work in public health.

So, what can you expect from the journal during this time of uncertainty? There are of course the traditional public health issues that will be covered. These are the very under-appreciated but essential public health functions that make living tolerable in this crowded world. Housing, STDs, AIDS (is it possible that this is already a traditional issue?), child labor, and ergonomic workplace standards are just a few of the issues that continue to perplex and need constant revisiting. There are also new challenges: performance standards and competencies, distance learning opportunities, emerging infectious diseases, the new administration's attitude toward public health, and more unreimbursed mandates for local public health departments such as inspection and certification of facilities involved with inherently risky behaviors such as tattooing and body piercing. Then, of course, there are the sometimes unwelcome role of public health agencies in the managed care debacle and the increasing weight of providing primary care for the working poor in a booming economy or the disenfranchised in a struggling economy. Finally there are those mind-boggling issues surrounding the use of the human genome data, bioengineered foods and medicines, and bioterrorism. What role will this journal play in addressing these questions?

PHR, with its partner the Association of Schools of Public Health, is going to seek out the best of academic thinking. We will find examples where public health practitioners are effectively taking lessons from the academic and research communities and molding these ideas into public health practice. We will provide historical and legal perspective. And, I believe most important, we will attempt to uncover disagreement and provoke debate. It is my hope that with the help of the readers and the contributors this journal will be the year-round meeting place for the public health community to gather as colleagues to discover and solve problems and intervene to make a difference.

A final note: for a long time now the journal has been caringly looked after by the Acting Editor, Judith Kurland, and Anne Fidler, CDC liaison to the Boston University School of Public Health. Judy Kaplan, Scientific Editor, and Maureen Osolnik of the DHHS Regional Director's office selflessly stepped in to manage the large volume of work that it takes to produce a publication like this. I am certain that when Judith and Anne accepted temporary oversight of the journal, they were thinking the search for a new editor might last as long as several months. Now almost two years later, they have transitioned management of PHR to me. Judith, Anne, Judy, and Maureen have seen to it that the journal continued publication with a solid array of pertinent public health feature articles, commentaries, and research papers. I certainly have some large shoes to fill. 